\title{
RESPOSTA SOROLÓGICA E AVALIAÇÃO DE PROTEÇÃO FETAL EM OVELHAS PRENHES VACINADAS CONTRA O VÍRUS DA DIARRÉIA VIRAL BOVINA (BVDV) ${ }^{1}$
}

\author{
SEROLOGICAL RESPONSE AND EVALUATION OF FETAL PROTECTION IN PREGNANT \\ EWES VACCINATED AGAINST BOVINE VIRAL DIARRHEA VIRUS (BVDV)
}

\author{
Fernanda Silveira Flores Vogel ${ }^{2}$ Charles Fernando Capinos Scherer ${ }^{2}$ Eduardo Furtado Flores $^{3}$ \\ Rudi Weiblen ${ }^{4}$ Marcelo de Lima $^{5}$ Cíntia Farias Kunrath $^{5}$
}

RESUMO

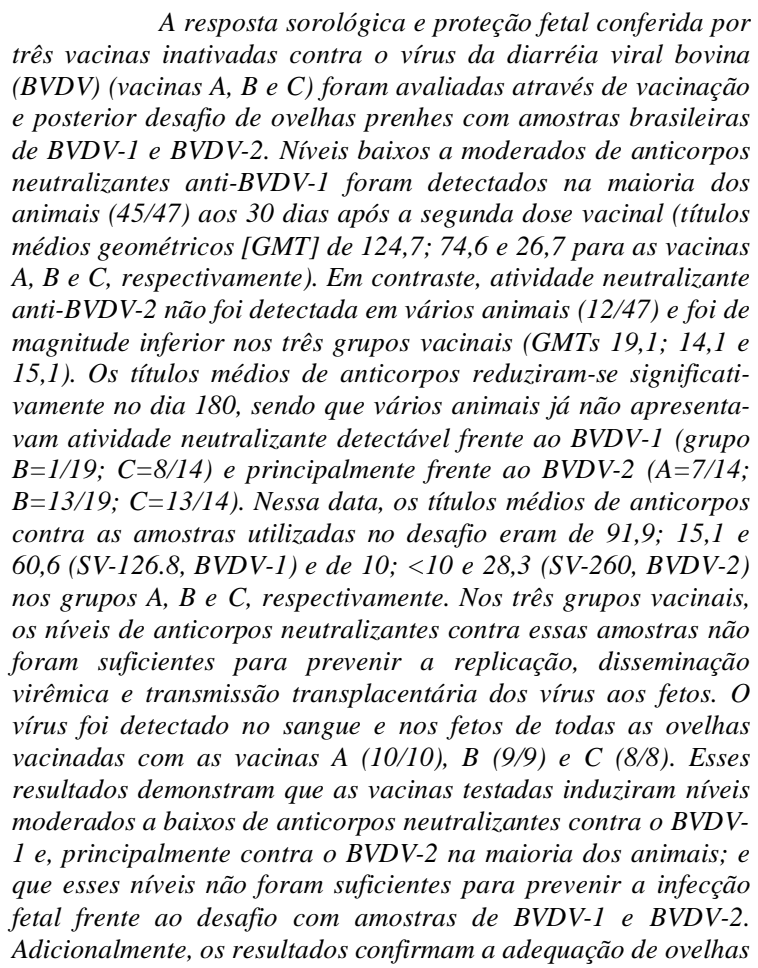

prenhes para estudos de proteção fetal por vacinas contra o $B V D V$. Palavras-chave: vírus da diarréia viral bovina, BVDV, vacinas,
proteção fetal, ovinos

\section{SUMMARY}

The serological response and fetal protection conferred by three bovine viral diarrhea virus (BVDV) inactivated vaccines (vaccines $A, B$ and $C$ ) were evaluated through immunization followed by challenge of pregnant ewes with Brazilian BVDV-1 and BVDV-2 field isolates. Moderate to low levels of anti-BVDV-1 neutralizing antibodies were detected in most animals (45/47) 30 days after the second vaccine administration (geometric mean titers [GMT] 124.7, 74.6 and 26.7 for vaccines $A, B$ and $C$, respectively). In contrast, neutralizing activity to BVDV-2 was not detected in several vaccinated animals (12/47) and was significantly lower than to $B V D V-1$ in all three vaccine groups (GMT 19.1, 14.1 and 15.1). The antibody levels declined significantly by day 180, such that some animals from groups $B$ (1/19) and $C$ (8/14) had no detectable neutralizing activity against $B V D V-1$; and several animals from groups $A(7 / 14), B$ (13/19) and $C$ (13/14) did not react against $B V D V-2$. At this time, the mean antibody titers against the challenge viruses were 91.9; 15.1 and 60.6 (SV-126.8, $B V D V-1)$; and 10; <10 and 28.3 (SV-260, BVDV-2) for vaccines $A, B$ and $C$, respectively. The antibody levels to the homologous viruses were not sufficient to prevent virus replication, viremia and transplacental transmission of the virus upon challenge. Infectious virus was detected in the blood of all vaccinated ewes and in their fetuses. These results demonstrate that the vaccines

\footnotetext{
${ }^{1}$ Parte da Dissertação de Mestrado dos dois primeiros autores ao Programa de Pós-graduação em Medicina Veterinária, Universidade Federal de Santa Maria (UFSM).

${ }^{2}$ Médico Veterinário, aluno do Programa de Pós-graduação em Medicina Veterinária, UFSM, Professor Substituto, Departamento de Microbiologia e Parasitologia, Centro de Ciências da Saúde, UFSM.

${ }^{3}$ Médico Veterinário, MSc, PhD, Professor Adjunto, Departamento de Medicina Veterinária Preventiva, Centro de Ciências Rurais e Departamento de Microbiologia e Parasitologia, UFSM. Bolsista do CNPq (520758/96-0). DMVP, CCR, UFSM, 97105-900, Santa Maria, RS. Fone/fax: 55-220-8034. E mail: flores@ccr.ufsm.br. Autor para correspondência.

${ }^{4}$ Médico Veterinário, MSc, PhD, Professor Titular, Departamento de Medicina Veterinária Preventiva e Departamento de Microbiologia e Parasitologia, UFSM. Bolsista do CNPq (520161/97-1).

${ }_{5}^{5}$ Acadêmico do Curso de Medicina Veterinária, UFSM. Bolsista de Iniciação Científica - CNPq/PIBIC/UFSM.
} 
tested induced low to moderate titers of antibody against BVDV-1 and even lower titers against BVDV-2 in most animals. The antibody levels declined progressively and were not sufficient to prevent fetal infection upon challenge with $B V D V-1$ and $B V D V-2$ at day180. In addition, these findings demonstrate that pregnant sheep represent an adequate model to study fetal protection by $B V D V$ vaccines.

Key words: bovine viral diarrhea virus, BVDV, vaccines, fetal protection, sheep

\section{INTRODUÇÃO}

O vírus da diarréia viral bovina (BVDV) é um dos principais patógenos de bovinos e causa perdas significativas à pecuária em todo o mundo (BAKER, 1995). O BVDV é um vírus RNA de polaridade positiva, com envelope, pertencente à família Flaviviridae, gênero Pestivírus. O gênero Pestivírus inclui ainda o vírus da doença da fronteira de ovinos (BDV) e o vírus da peste suína clássica (CSFV, FRANCKI et al., 1991). Os pestivírus apresentam uma grande variabilidade antigênica, embora o estabelecimento definitivo de sorotipos ainda não tenha sido possível (EDWARDS \& PATON, 1995). No entanto, dois grupos antigenicamente distintos do BVDV já foram identificados - BVDV-1 e BVDV-2 (PELLERIN et al., 1994). Amostras de campo do BVDV podem ser ainda diferenciadas em biotipos citopático (CP) e não-citopático (NCP), de acordo com a capacidade de produzir citopatologia em cultivo celular (BROWNLIE, 1990).

Além de infecções subclínicas, a infecção pelo BVDV pode resultar em várias manifestações clínicas que incluem doença respiratória ou digestiva (diarréia viral bovina, BVD), doença das mucosas (DM) e BVD aguda/hemorrágica (BAKER, 1995). A infecção de fêmeas soronegativas geralmente resulta em transmissão transplacentária do vírus para o feto. As consequiências da infecção intrauterina são determinadas pela idade gestacional e por propriedades do vírus (MOENNIG \& LIESS, 1995). Mortalidade embrionária ou fetal, abortos, mumificação, malformações fetais e o nascimento de bezerros fracos e inviáveis estão entre as conseqüências da infecção de fetos bovinos com o BVDV. Infecção de fêmeas prenhes entre os dias 40 e 120 de gestação com amostras NCP pode resultar em imunotolerância fetal e no nascimento de bezerros persistentemente infectados (PI). Os animais PI eliminam o vírus continuamente em secreções e excreções e constituem-se na principal fonte de disseminação do vírus (BROWNLIE, 1990; BAKER, 1995).
A prevenção da infecção fetal e o conseqüente nascimento de animais PI constitui-se no pontochave do controle da infecção pelo BVDV (DUBOVI, 1992). Isso pode ser obtido pela vacinação de fêmeas susceptíveis, além da identificação e eliminação de animais PI (DUBOVI, 1992; BOLIN, 1995). Várias vacinas com vírus vivo modificado (VVM) e com vírus inativado têm sido utilizadas com esse objetivo (BOLIN, 1995). Atualmente, todas as vacinas licenciadas contra o BVDV no Brasil são formuladas com vírus inativado. A proteção conferida por vacinas inativadas é geralmente de magnitude e duração inferiores à proteção conferida pelas vacinas com VVM (BOLIN, 1995). Além disso, a grande variabilidade antigênica do vírus dificulta a obtenção de proteção contra o amplo espectro antigênico dos isolados de campo (DUBOVI, 1992).

Os ovinos são susceptíveis à infecção natural e experimental com o BVDV (LOKEN, 1995). Inoculação experimental de ovelhas prenhes resulta em transmissão do vírus ao feto, podendo resultar em mortalidade embrionária ou fetal, abortos, mumificações, malformações, natimortalidade e nascimento de cordeiros PI (SCHERER et al., 2001). Esses estudos demonstram que a biologia da infecção pelo BVDV em ovelhas prenhes é muito semelhante à infecção na espécie bovina. A susceptibilidade de ovinos à infecção pelo BVDV e, em especial, as consequiências da infecção sobre a gestação e o feto, indicam que essa espécie pode ser utilizada como modelo para estudos de patogenia e proteção vacinal. Os objetivos do presente estudo foram quantificar a resposta sorológica e avaliar a proteção fetal conferida por três vacinas inativadas contra o BVDV, utilizando ovelhas prenhes como modelo.

\section{MATERIAL E MÉTODOS}

Ovelhas adultas foram divididas em três grupos, e cada grupo recebeu duas doses de uma vacina comercial contra o BVDV com intervalo de 30 a 40 dias. Trinta dias após a segunda vacinação, os animais foram colocados em cobertura. Quarenta e cinco dias após o final da temporada de monta, as ovelhas prenhes foram identificadas através de ultrasonografia. Ovelhas prenhes de cada grupo vacinal foram então inoculadas com amostras de BVDV-1 ou BVDV-2 pela via intranasal. Dezenove dias após o desafio, os animais foram sacrificados e tecidos maternos e fetais foram coletados para pesquisa de vírus. A resposta à vacinação foi avaliada através de testes sorológicos e pela capacidade das vacinas em prevenir a infecção fetal. 
Células e vírus - Os procedimentos de multiplicação, isolamento e quantificação de vírus e testes de soroneutralização (SN) foram realizados com células MDBK (Madin Darby bovine kidney; American Type Culture Collection, CCL-22) livres de pestivírus. As células foram cultivadas em meio essencial mínimo(MEM), com penicilina $(35 \mathrm{mg} / \mathrm{L})$, estreptomicina $(200 \mathrm{mg} / \mathrm{L})$, suplementado com $5 \%$ de soro eqüino. As cepas padrão de BVDV tipo 1 e 2 (Singer e VS-253, respectivamente) foram cedidas pelo Dr Ruben Donis (University of Nebraska at Lincoln, Lincoln, NE, USA). As amostras de BVDV-1 (SV-126.8) e 2 (SV-260) utilizadas para o desafio dos animais vacinados foram isoladas e caracterizadas no setor de Virologia da UFSM (BOTTON et al., 1998; GIL, 1998).

Animais, vacinas e protocolo de vacinação - Foram utilizadas ovelhas das raças Corriedale e Ideal, soronegativas ao BVDV, com idade entre dois e quatro anos e com bom estado nutricional, provenientes de duas propriedades. Os animais foram divididos aleatoriamente em quatro grupos. Três grupos foram vacinados $(\mathrm{A}, \mathrm{n}=14 ; \mathrm{B}, \mathrm{n}=19$ e $\mathrm{C}$, $\mathrm{n}=14$ ) e um permaneceu como controle nãovacinado $(D, n=20)$. Foram utilizadas três vacinas comerciais contra o BVDV (vacinas A, B e C). Essas vacinas contêm cepas citopáticas e nãocitopáticas do BVDV inativadas, além de antígenos de outros patógenos de bovinos. A identidade das cepas vacinais não são informadas pelos fabricantes. Essas vacinas são indicadas para a imunização de bovinos ( $5 \mathrm{ml}$ por via intramuscular ou subcutânea) e foram administradas de acordo com o protocolo dos fabricantes: primovacinação e revacinação 30 a 40 dias após. Noventa dias após a primeira vacinação, as ovelhas foram colocadas em cobertura durante 45 dias. Quarenta e cinco dias após o final da temporada de monta, os animais foram submetidos a exames ultra-sonográficos para diagnóstico de gestação. Algumas ovelhas prenhes de cada grupo $(A=10 ; B=9$ e $C=8)$ foram separadas do restante do grupo e submetidas ao desafio.

Resposta sorológica - Amostras de soro coletadas no dia da primeira vacinação (dia 0 ); no dia da segunda dose da vacina (dia 30); trinta dias após (dia 60) e no dia do desafio (dia 180); foram testadas para a presença de anticorpos neutralizantes contra o BVDV, através da técnica de soroneutralização $(\mathrm{SN})$. Os testes foram realizados em duplicata, testando-se cada amostra de soro contra um vírus do genótipo 1 (BVDV-1, cepa Singer) e do genótipo 2 (BVDV-2, cepa VS-253). Amostras de soro dos animais desafiados, coletadas no dia do desafio, também foram testadas frente ao vírus ino- culado (SV-126.8 ou SV-260). Os testes de SN foram realizados em placas de poliestireno de 96 cavidades, utilizando diluições crescentes de soro (partindo de 1:10) frente a doses constantes de vírus (100 DICC $_{50}$ - doses infectantes para 50\% dos cultivos celulares/cavidade) e células MDBK como indicador. A leitura dos testes foi realizada após $96 \mathrm{~h}$ de incubação, através do monitoramento do efeito citopático ou detecção de antígenos virais por imunofluorescência. Os títulos de anticorpos neutralizantes foram expressos como as recíprocas das maiores diluições do soro capazes de prevenir a replicação viral. Para o cálculo das médias, foram utilizados os títulos de anticorpos de todas as ovelhas de cada grupo, incluindo os animais que não foram submetidos ao desafio. As médias dos títulos foram transformadas em títulos médios geométricos (GMT; THRUSFIELD, 1986) pela relação: $G M T=2^{\mathrm{a}}$, onde a é a média do $\log _{\mathrm{a}}$ do título de anticorpos em cada vacina e em cada genótipo viral. Para esse cálculo, somente foram considerados os valores dos animais que reagiram positivamente no teste de $\mathrm{SN}$ (títulos $\geq 10$ ). A comparação entre as médias foi realizada através de análise de variância pelo teste $\mathrm{F}$ e teste de Tukey, com nível de significância de 5\%.

Avaliação de proteção fetal - Para avaliação de proteção fetal, ovelhas prenhes dos três grupos vacinais (grupo $A, n=10 ; B, n=9$ e $C, n=8$ ) e do grupo controle $(\mathrm{D}, \mathrm{n}=8)$ foram inoculadas com duas amostras de campo do BVDV. Para isso, cada grupo foi dividido em dois e os animais de cada subgrupo foram inoculados com uma amostra de BVDV-1 (SV-126.8) ou BVDV-2 (SV-260). Os animais foram inoculados com $5 \mathrm{ml}$ de suspensão contendo aproximadamente $10^{7}$ DICC $_{50}$ de vírus, pela via intranasal. Sangue para pesquisa de vírus foi coletado dos animais inoculados nos dias 3 e 5 pósinoculação (pi). Dezenove dias após a inoculação, os animais foram sacrificados para coleta de material para pesquisa de vírus (placentomas; líquidos, sangue, rins, baço, timo e pulmões fetais). Para a pesquisa de vírus, os tecidos foram pesados, macerados com areia estéril e ressuspendidos em MEM (10\% peso/volume). Após, o material foi centrifugado a $8.000 \times \mathrm{g}$ durante $5 \mathrm{~min}$. Uma alíquota $(0,5 \mathrm{ml})$ do sobrenadante foi inoculada em células MDBK cultivadas em placas de 24 cavidades. O material foi submetido a duas passagens de quatro dias cada. No final da segunda passagem, as células foram submetidas à técnica de imunofluorescência indireta para detecção de antígenos virais (BOTTON et al., 1998). $\mathrm{O}$ isolamento do vírus do sangue foi realizado através da inoculação da capa flogística em células MDBK e monitoramento como descrito acima. 


\section{RESULTADOS}

Os resultados da avaliação sorológica dos animais vacinados e dos testes de proteção estão resumidos na tabela 1 . Nos dias 30,60 e 180 os animais vacinados com a vacina $A$ apresentaram títulos médios de anticorpos anti-BVDV-1 superiores aos vacinados com as vacinas B e C. Essas diferenças, no entanto, não foram estatisticamente significativas. Os títulos anti-BVDV-2 induzidos pelas três vacinas foram menos variáveis entre si e foram significativamente inferiores aos títulos anti-BVDV$1(\mathrm{p}<0,05)$, com exceção da vacina $\mathrm{C}$ no dia 180 . O maior número de animais reagentes, assim como os maiores títulos de anticorpos foram detectados no dia 60. Nessa data, 95,8\% (45/47) dos animais vacinados apresentava anticorpos contra o BVDV-1 e $74,5 \%$ (35/47) reagiram contra o BVDV-2. A partir do dia 60, os títulos reduziram-se progressivamente, atingindo níveis baixos no dia 180. Nessa data, 9 $(18,7 \%)$ e $33(70,2 \%)$ dos animais vacinados já não apresentaram atividade neutralizante detectável no soro contra o BVDV-1 e BVDV-2, respectivamente. Após o desafio, os animais controle e todos os vacinados apresentaram viremia, detectada em pelo menos uma das coletas. Os títulos de vírus no sangue e a duração da viremia, no entanto, não foram determinados, não permitindo a comparação entre os grupos vacinais e o grupo controle.

Os resultados dos testes de proteção fetal, assim como os títulos individuais de anticorpos contra as amostras de vírus utilizadas no desafio estão apresentados na tabela 2. Os títulos médios de anticorpos contra o BVDV-1 (SV-126.8) no dia do desafio foram de 91,9; 15,1 e 60,6 para as vacinas A, B e C, respectivamente. Nesse dia, apenas os animais vacinados com a vacina $\mathrm{A}$ e $\mathrm{C}$ apresentaram níveis detectáveis de anticorpos neutralizantes contra a amostra de BVDV-2 (SV-260, GMT 10 e 28,3). O vírus foi detectado no feto de todas as ovelhas vacinadas e controles, independentemente do grupo vacinal e do vírus utilizado no desafio. Pequenas diferenças na distribuição de vírus em tecidos fetais foram observadas entre os grupos vacinais e entre esses e o grupo controle. Esses resultados demonstraram que os títulos de anticorpos contra as amostras homólogas presentes no dia do desafio (180 dias após a primeira dose vacinal) não foram suficientes para prevenir a transmissão transplacentária do vírus aos fetos.
Tabela 1 - Resposta sorológica, viremia e infecção fetal em ovelhas imunizadas com vacinas inativadas e posteriormente desafiadas com o vírus da diarréia viral bovina (BVDV).

\begin{tabular}{|c|c|c|c|c|c|c|}
\hline \multirow{4}{*}{ Vacina } & \multirow{4}{*}{ Dia } & \multicolumn{2}{|c|}{ Resposta sorológica $^{\mathrm{a}}$} & \multirow{4}{*}{$\begin{array}{l}\text { Relação }^{d} \\
\text { BVDV-1/2 }\end{array}$} & \multirow{4}{*}{$\frac{\text { Viremia }^{\mathrm{e}}}{\text { Positivas/ }_{\text {total }^{\mathrm{f}}}}$} & \multirow{4}{*}{$\begin{array}{l}\frac{\text { Infecção fetal }}{\text { Vírus do desafio }} \\
\text { SV-126.8 SV-260 }\end{array}$} \\
\hline & & \multirow{2}{*}{ BVDV-1 } & \multirow{2}{*}{ BVDV-2 } & & & \\
\hline & & & & & & \\
\hline & & Positivos $^{\mathrm{b}}$ Título $^{\mathrm{c}}$ & Positivos Título & & & \\
\hline
\end{tabular}

\begin{tabular}{|c|c|c|c|c|c|c|c|c|c|}
\hline \multirow[t]{3}{*}{ A } & 30 & $13 / 14$ & $29,1(0-160)$ & $7 / 14$ & $12,1(0-20)$ & 2,4 & & & \\
\hline & 60 & $14 / 14$ & $124,6(20-320)$ & $14 / 14$ & $19,1(10-80)$ & 6,5 & & & \\
\hline & 180 & $14 / 14$ & $24,3(10-80)$ & $7 / 14$ & $10,0(0-10)$ & 2,4 & $10 / 10$ & $5 / 5$ & $5 / 5$ \\
\hline \multirow[t]{3}{*}{ B } & 30 & $15 / 19$ & $16,6(0-80)$ & $3 / 19$ & $10,0(0-10)$ & 1,6 & & & \\
\hline & 60 & $19 / 19$ & $74,6(10-320)$ & $16 / 19$ & $14,1(0-80)$ & 5,3 & & & \\
\hline & 180 & $18 / 19$ & $19,3(0-160)$ & $6 / 19$ & $12,6(0-40)$ & 1,5 & $9 / 9$ & $5 / 5$ & $4 / 4$ \\
\hline \multirow[t]{3}{*}{$\mathrm{C}$} & 30 & $11 / 14$ & $15,6(0-80)$ & $5 / 14$ & $13,2(0-20)$ & 1,2 & & & \\
\hline & 60 & $12 / 14$ & $26,8(0-320)$ & $5 / 14$ & $15,1(0-40)$ & 1,7 & & & \\
\hline & 180 & $6 / 14$ & $15,9(0-40)$ & $1 / 14$ & $20,0(0-20)$ & 0,8 & $8 / 8$ & $5 / 5$ & $3 / 3$ \\
\hline Controle & & $0 / 20$ & $\mathrm{na}^{\mathrm{g}}$ & $0 / 20$ & na & na & $8 / 8$ & $4 / 4$ & $4 / 4$ \\
\hline
\end{tabular}

Título de anticorpos neutralizantes frente ao BVDV-1 (cepa Singer) e BVDV-2 (VS-253) nos respectivos dias de coleta.

${ }^{\mathrm{b}}$ Número de animais que reagiu sorologicamente à vacinação/total de vacinados.

'Título médio geométrico (GMT) e variação. Na variação, zero (0) significa negativo na menor diluição do soro (1:10).

${ }^{\mathrm{d}}$ Relação entre os títulos de anticorpos frente ao BVDV-1 e BVDV-2 .

e Detecção de vírus na capa flogística dos animais inoculados, em material coletado nos dias 3 e 5 pós desafio.

${ }^{\mathrm{f}} \mathrm{O}$ denominador indica o número de animais de cada grupo que foi submetido ao desafio

${ }^{\mathrm{g}}$ Não aplicável. Os animais controle permaneceram soronegativos durante o experimento.

\section{DISCUSSÃO}

A vacinação e o posterior desafio de ovelhas prenhes com amostras de BVDV-1 e BVDV-2 permitiu avaliar a resposta sorológica e a proteção fetal conferida por três vacinas comerciais contra o BVDV. As três vacinas induziram títulos moderados a baixos de anticorpos neutralizantes contra $\mathrm{O}$ BVDV-1 e de magnitude ainda inferior contra $o$ BVDV-2. Os níveis de anticorpos induzidos pela vacinação reduziram-se significativamente e não foram suficientes para prevenir a disseminação virêmica e transmissão transplacentária do vírus aos fetos frente ao desafio realizado seis meses após a vacinação. Os resultados de um experimento realizado em paralelo, no qual 
Tabela 2 - Detecção de vírus na placenta e em tecidos de fetos de ovelhas imunizadas com vacinas inativadas e posteriormente desafiadas com o vírus da Diarréia Viral Bovina (BVDV).

\begin{tabular}{|c|c|c|c|c|c|c|c|c|c|c|}
\hline \multirow{3}{*}{ Vacina } & \multirow{3}{*}{ Animal } & \multirow{3}{*}{$\mathrm{SN}^{\mathrm{a}}$} & \multirow{3}{*}{$\begin{array}{c}\text { Desafio } \\
\text { (vírus) }\end{array}$} & \multicolumn{7}{|c|}{ Vírus } \\
\hline & & & & \multicolumn{7}{|c|}{ Feto } \\
\hline & & & & Placentoma & Líquidos & Sangue & Baço & Pulmão & $\operatorname{Rim}$ & Timo \\
\hline \multirow[t]{10}{*}{ A } & 3 & 80 & SV-126.8 & $-{ }^{b}$ & $++^{\mathrm{c}}$ & - & + & - & + & + \\
\hline & 4 & 80 & & + & + & - & - & + & + & + \\
\hline & 5 & 160 & & + & + & + & + & - & - & - \\
\hline & 13 & 40 & & + & + & - & + & - & - & + \\
\hline & 138 & 160 & & + & + & - & - & + & + & - \\
\hline & 2 & $<10^{\mathrm{d}}$ & SV-260 & - & - & + & - & + & - & - \\
\hline & 7 & $<10$ & & + & + & + & + & - & - & + \\
\hline & 10 & 10 & & + & + & - & - & + & - & + \\
\hline & 20 & 10 & & + & + & + & - & - & - & + \\
\hline & 34 & 10 & & + & + & - & + & + & - & + \\
\hline \multirow[t]{9}{*}{$\mathrm{B}$} & 36 & 10 & SV-126.8 & + & + & + & + & + & + & + \\
\hline & 37 & 160 & & + & + & + & + & + & + & + \\
\hline & 123 & 20 & & - & - & + & + & - & - & - \\
\hline & 132 & 80 & & + & + & - & - & - & - & - \\
\hline & 141 & 10 & & + & + & + & + & + & + & + \\
\hline & 157 & $<10$ & SV-260 & + & - & - & - & - & + & - \\
\hline & 136 & $<10$ & & + & + & + & + & - & - & + \\
\hline & 124 & $<10$ & & + & + & + & + & + & + & + \\
\hline & 38 & $<10$ & & - & - & + & + & - & + & - \\
\hline \multirow[t]{8}{*}{$\mathrm{C}$} & 43 & 80 & SV-126.8 & - & + & - & - & - & - & - \\
\hline & 44 & 80 & & - & + & + & - & - & + & - \\
\hline & 22 & 40 & & - & + & + & + & - & - & + \\
\hline & 24 & 10 & & + & - & + & - & - & - & - \\
\hline & 28 & $>320$ & & + & + & - & + & - & + & + \\
\hline & 21 & 10 & SV-260 & - & - & - & + & - & + & - \\
\hline & 25 & 40 & & - & + & - & + & - & + & - \\
\hline & 42 & $<10$ & & + & + & - & - & - & + & - \\
\hline \multirow[t]{8}{*}{ Controles } & 94 & $<10$ & SV-126.8 & + & + & + & + & + & - & + \\
\hline & 96 & $<10$ & & + & - & - & + & - & + & + \\
\hline & 98 & $<10$ & & + & - & + & - & - & + & + \\
\hline & 99 & $<10$ & & + & + & + & + & + & + & + \\
\hline & 86 & $<10$ & SV-260 & - & - & - & + & + & + & + \\
\hline & 87 & $<10$ & & + & - & + & + & + & + & + \\
\hline & 173 & $<10$ & & + & + & + & + & - & + & - \\
\hline & 137 & $<10$ & & + & + & - & - & + & + & + \\
\hline
\end{tabular}

${ }^{a}$ Título de anticorpos neutralizantes contra a amostra homóloga (SV-126.8 ou SV-260), no soro coletado no dia do desafio.

${ }^{\mathrm{b}}$ Negativo para vírus.

${ }^{\mathrm{c}}$ Positivo para vírus.

${ }^{\mathrm{d}}$ Teste de SN negativo na menor diluição do soro utilizada (1:10).

bovinos jovens foram vacinados com as mesmas vacinas e avaliados sorologicamente a diferentes intervalos, corroboram essas observações. A magnitude, evolução e duração dos anticorpos neutralizantes produzidos pela vacinação desses bovinos foi muito semelhante aos observados no presente estudo (VOGEL et al., 2002). Os resultados do presente estudo também demonstram a adequação de ovelhas prenhes para avaliações de resposta sorológica e proteção fetal por vacinas contra o BVDV.

As duas amostras de vírus utilizadas no desafio (SV-126.8 e SV-260) replicaram com efici- ência nos animais inoculados, resultando em viremia e infecção fetal na totalidade dos fetos. A escolha do vírus para o desafio é crítica em experimentos de proteção fetal, pois a utilização de isolados que não repliquem com eficiência no hospedeiro e que não sejam transmitidos à totalidade dos fetos pode levar a resultados pouco conclusivos (BROWNLIE et al., 1995; BRUSCHKE et al., 1997; PATON et al., 1999). Além dessas características, as amostras SV126.8 e SV-260 foram utilizadas por representarem amostras brasileiras de BVDV-1 e BVDV-2 bem caracterizadas antigênica e geneticamente 
(BOTTON et al., 1998; GIL, 1998). O procedimento utilizado para a detecção de infecção fetal exigiu o sacrifício das ovelhas para a coleta de material. No entanto, essa abordagem facilitou e abreviou o experimento, pois dispensou o monitoramento dos animais no restante da gestação, como têm sido realizado em outros estudos (BROWNLIE et al., 1995; CORTESE et al., 1998a). Independente das conseqüências da infecção fetal, a detecção de vírus em tecidos fetais após a inoculação é um indicativo objetivo da transmissão congênita do vírus.

A resposta sorológica induzida pela primeira dose das vacinas foi baixa e pouco consistente. Oito animais (17\%) não apresentaram sorologia positiva ao BVDV-1 e $32(68,1 \%)$ não apresentaram atividade neutralizante contra o BVDV-2 aos 30 dias. Apenas no dia 60 (30 dias após a segunda dose), a maioria dos animais apresentou títulos de anticorpos, embora de magnitude baixa a moderada. Ainda assim, esses títulos foram muito variáveis, sendo que vários animais de dois grupos vacinais (B e C) não apresentaram atividade neutralizante contra o BVDV-2 nessa data. A duração dos níveis de anticorpos também foi limitada e os títulos médios reduziram-se significativamente aos 180 dias. Como tem sido demonstrado em outros estudos, os níveis de anticorpos induzidos por vacinas inativadas geralmente decrescem gradativa e rapidamente, atingindo níveis baixos 6 a 8 meses após a vacinação (CORTESE $\boldsymbol{e}$ t al., 1998b; FULTON \& BURGE, 2000). Por isso, o uso dessas vacinas obrigatoriamente requer revacinações anuais ou a intervalos menores para a manutenção de níveis adequados de anticorpos. Ao contrário, vacinas com vírus vivo modificado geralmente induzem uma resposta neutralizante de magnitude, espectro e duração maiores, dispensando muitas vezes a necessidade de revacinação (BOLIN, 1995). No presente experimento, além dos títulos médios baixos aos 180 dias, uma parcela significativa dos animais não apresentou atividade neutralizante detectável contra o BVDV-1 (9/47) e, principalmente contra o BVDV-2 (33/47). Nesse caso, a aplicação de um reforço anual, como recomendado pelos fabricantes, poderia resultar em uma resposta anamnéstica com aumento dos títulos de anticorpos.

A atividade neutralizante anti-BVDV-1 foi superior à anti-BVDV-2 no soro dos animais vacinados, tanto para as cepas utilizadas nos testes de SN como para as amostras do desafio. Essas diferenças refletem a formulação atual da maioria das vacinas, que contém apenas cepas de BVDV-1 (Van OIRSCHOT et al., 1999; FULTON \& BURGE, 2000). Apenas recentemente, vacinas contendo vírus dos dois genótipos começaram a ser produzidas e comercializadas na América do Norte (RIDPATH - comunicação pessoal). Diferenças de títulos neutralizantes de até 128 vezes já foram detectadas entre cepas vacinais norte-americanas de BVDV-1 e amostras brasileiras de BVDV-2 (BOTTON et al., 1998). A baixa reatividade sorológica entre amostras de BVDV-1 e BVDV-2, além da grande diversidade antigênica entre vírus do mesmo genótipo, são provavelmente os principais responsáveis pelos insucessos ou falhas vacinais freqüentemente relatados. No presente experimento, as diferenças entre os títulos vacinais anti-BVDV-1 e antiBVDV-2 foram estatisticamente significativas, atingindo os maiores valores no pico dos níveis de anticorpos, aos 30 dias após a segunda dose (dia 60). Nessa data, a relação entre títulos neutralizantes BVDV-1/BVDV-2 atingiu 6,5 e 5,3 para as vacinas A e B, respectivamente. No entanto, essas diferenças foram inferiores às relatadas por BOTTON et al. (1998) e FULTON \& BURGE (2000), não atingindo valores maiores provavelmente devido aos níveis moderados e baixos de anticorpos induzidos pelas vacinas.

Aos 180 dias, os títulos de anticorpos neutralizantes dos animais dos grupos A e C contra a amostra de BVDV-1 utilizada no desafio (SV-126.8) foram superiores aos títulos contra a cepa utilizada nos testes de SN (Singer). Isso provavelmente reflete uma maior similaridade antigênica entre a amostra SV-126.8 e as cepas vacinais. Em contraste, os títulos contra a amostra de BVDV-2 do desafio (SV260) não diferiram muito dos títulos contra a cepa de BVDV-2 utilizada nos testes de SN (VS-253). Independente da especificidade, grupo vacinal e variações de magnitude, os níveis de anticorpos presentes no soro no dia 180 não impediram a replicação, disseminação sistêmica e transmissão do vírus aos fetos. Todas as ovelhas desafiadas apresentaram viremia em, pelo menos, uma das coletas, e os fetos de todas as ovelhas vacinadas continham o vírus em líquidos ou tecidos. A ausência de proteção fetal nos animais vacinados e inoculados com a amostra SV260 (BVDV-2) não foi surpreendente, considerando a atividade neutralizante baixa ou indetectável frente à amostra homóloga detectada no soro da maioria dos animais. No entanto, mesmo alguns animais com títulos de magnitude média (160 e 320) contra a amostra SV-126.8 não ficaram protegidos da infecção fetal. As diferenças de distribuição de vírus nos tecidos são pouco relevantes nesse contexto. É possível que a realização do desafio a um intervalo menor após a vacinação, quando os níveis de anticorpos eram mais altos, resultasse em algum grau de proteção fetal. Em condições naturais, no entanto, é mais provável que o contato de animais vacinados 
com o vírus ocorra a intervalos variados e, muitas vezes, longos após a vacinação. Da mesma forma, a dose de vírus e a via intranasal de inoculação utilizada no desafio são provavelmente compatíveis com as infecções naturais pelo BVDV, sobretudo pela exposição a animais PI, que excretam grandes quantidades do vírus.

A proteção fetal conferida pela vacinação contra o BVDV é freqüentemente incompleta, sobretudo frente a desafio com amostras antigenicamente diferentes das cepas vacinais (HARKNESS $\boldsymbol{e t}$ al., 1987; DUBOVI, 1992). O acompanhamento de rebanhos regularmente vacinados contra o BVDV têm confirmado a proteção fetal insuficiente, pois perdas reprodutivas e animais PI continuam a ser produzidos nesses rebanhos (BOLIN et al., 1991; DUBOVI, 1992). Níveis de anticorpos neutralizantes pré-desafio parecem não ser um indicativo seguro do grau de proteção fetal conferido pela vacinação (PATON et al., 1999). Vários estudos têm falhado em demonstrar correlação entre títulos de anticorpos neutralizantes in vitro e proteção fetal in vivo contra o BVDV (BRUSCHKE et al., 1997; 1999; PATON et al., 1999). Anticorpos neutralizantes em títulos altos (2048 e até 4096) produzidos por vacinas inativadas ou de subunidades virais podem ser insuficientes para prevenir a infecção fetal contra vírus heterólogos e mesmo contra o vírus homólogo em ovinos (BRUSCHKE et al., 1997; 1999). No presente estudo, títulos neutralizantes de 160 e 320 contra a amostra homóloga induzidos por vacinas inativadas foram incapazes de proteger o feto da infecção após desafio pela via intranasal. Em contraste, títulos neutralizantes de magnitude moderada ou relativamente baixa produzidos por vacinas com vírus vivo modificado (PATON et al., 1999) ou inativado (BROWNLIE et al., 1995) têm sido associados à proteção fetal em ovinos e bovinos, respectivamente. Essas observações sugerem que imunidade mediada por células, e que anticorpos sem atividade neutralizante, podem estar envolvidos na prevenção da transmissão transplacentária do BVDV ao feto (BRUSCHKE et al., 1997; 1999). Por isso, vacinas com vírus vivo modificado, que induzem resposta humoral e celular mediada por linfócitos $\mathrm{T}$ citotóxicos seriam certamente mais eficientes na indução de proteção fetal. De qualquer forma, devido à grande variabilidade antigênica do BVDV, exposição ou vacinação com uma determinada cepa viral não asseguram proteção fetal cruzada contra o amplo espectro antigênico dos isolados de campo (DUBOVI, 1992; PATON et al., 1999).

As vacinas utilizadas nesse experimento (assim como virtualmente todas as vacinas contra o BVDV) são indicadas para proteção da doença clíni- ca, não se referindo especificamente à proteção fetal. No entanto, sabe-se que a prevenção da infecção fetal e a conseqüente geração de animais PI é o ponto-chave no controle da infecção pelo BVDV. Por isso, esforços têm sido concentrados para desenvolver vacinas que confiram proteção fetal satisfatória. Nesse sentido, é mais provável que vacinas com vírus vivo modificado e contendo várias cepas antigenicamente diferentes entre si possam ter sucesso em prevenir a infecção fetal. Essas vacinas poderiam induzir uma resposta celular e humoral de grande magnitude e duração, conferindo proteção contra um espectro mais amplo de amostras de campo. Aliadas à medidas que evitem ou minimizem o contato de animais gestantes com animais potencialmente infectados, vacinas com essas características utilizadas de forma sistemática certamente teriam um papel decisivo na redução da circulação do vírus e do impacto da infecção na população bovina.

Comunicação Pessoal: Dra Julia Ridpath. National Animal Disease Center, NADC/ARS/USDA. Ames, Iowa. 50010. Estados Unidos.jridpath@nadc.ars.usda.gov.

\section{REFERÊNCIAS BIBLIOGRÁFICAS}

BAKER, J.C. Clinical manifestations of bovine viral diarrhea infection. Vet Clin North Amer, v.11, p.425-445, 1995.

BOLIN, S.R., LITTLEDIKE, E.T., RIDPATH, J.F. Serologic detection and practical consequences of antigenic diversity among bovine viral diarrhea virus in a vaccinated herd. Am J Vet Res, v.52, p.1033-1047, 1991.

BOLIN, S. R. Control of bovine viral diarrhea infection by use of vaccination. Vet Clin North Amer, v.11, p.615-625, 1995.

BOTTON, S.A., SILVA, A.M., BRUM, M.C.S., et al. Antigenic characterization of Brazilian isolates of bovine viral diarrhea virus (BVDV) with monoclonal antibodies and by crossneutralization. Braz J Med Biol Res, v.31, p.14291438,1998 .

BROWNLIE, J. The pathogenesis of bovine viral diarrhea virus infections. Rev Sci Tech, v.9, p.43-59, 1990.

BROWNLIE, J., CLARKE, M.C., HOOPER, L.B., et al. Protection of the bovine fetus from bovine viral diarrhoea virus by means of a new inactivated vaccine. Vet Rec, v.7, p.58-62, 1995.

BRUSCHKE, C.J.M., MOORMANN, R.J.M., Van OIRSCHOT, J.T., et al. A subunit vaccine based on glycoprotein E2 of bovine virus diarrhoea virus induces fetal protection in sheep against homologous challenge. Vaccine, v.15, p.1940-1945, 1997.

BRUSCHKE, C.J.M., Van OIRSCHOT, J.T., Van RIJN, P.A. An experimental multivalent bovine virus diarrhoea virus E2 subunit vaccine and two experimental conventionally inactived vaccines induce partial fetal protection in sheep. Vaccine, v.17, p. 1983-1991, 1999. 
CORTESE, V.S., GROOMS, D.L., ELLIS, J., et al. Protection of pregnant cattle and their fetuses against infection with bovine viral diarrhea virus type 1 by use of a modified-live virus vaccine. Am J Vet Res, v.59, p.1409-1413, 1998a.

CORTESE, V.S., WHITTAKER, R., ELLIS, J., et al. Specificity and duration of neutralizing antibodies induced in healthy cattle after administration of a modified-live virus vaccine against bovine viral diarrhea. Am J Vet Res, v.59, 848-850, $1998 b$

DUBOVI, E. J. Genetic diversity and BVD virus. Comp Immun Microbiol Dis, v.15, p.155-162, 1992

EDWARDS, S., PATON, D. Antigenic diferences among pestiviruses. Vet Clin North Amer, v.11, p.563-577, 1995

FRANCKI, R., FAUQUET, C., KNUDSON, D., et al. Classification and nomenclature of viruses. Arch Virol, v.2, suppl.2, p.223427, 1991. (Fifth Report of the International Committee on Taxonomy of Viruses. Wien and New York: Springer-Verlag).

FULTON, R.W., BURGE, L.J. Bovine viral diarrhea types 1 and 2 antibody response in calves receiving modified live virus or inactived vaccines. Vaccine, v.19, p.264-274, 2000.

GIL, L.H.V.G. Seqüenciamento, análise filogenética e caracterização de polipeptídeos não-estruturais de amostras do vírus da diarréia viral bovina. Santa Maria- RS, 1998. 67p. Dissertação (Mestrado em Medicina Veterinária) - Curso de Pós-graduação em Medicina Veterinária, Universidade Federal de Santa Maria, 1998

HARKNESS, J.W., ROEDER, P.L., DREW, T., et al. Pestivirus infection of ruminants. Brussels : CEC, 1987. 233p.
LOKEN, T. Border disease in sheep. Vet Clin North Amer, v.11, p.579 - 595, 1995.

MOENNIG, V., LIESS, B. Pathogenesis of intrauterine infections with bovine viral diarrhea virus. Vet Clin North Amer, v.11, p.477-487, 1995.

PATON, D.J., SHARP, G., IBATA, G. Foetal cross-protection experiments between type 1 and type 2 bovine viral diarrhoea virus in pregnant ewes. Vet Microbiol, v.64, p.185-196, 1999.

PELlERIN, C., VAN DEN HURK, J., LECOMTE, J. Identification of a new group of bovine viral diarrhea virus strains associated with severe outbreaks and high mortalities. Virology, v.203, p.260-267, 1994

SCHERER, C.F.C., FLORES, E.F., WEIBLEN, R., et al Experimental infection of pregnant sheep with bovine viral diarrhea type 2 (BVDV-2): effects on the pregnancy and fetus. Vet Microbiol, v.79, p.285-299, 2001.

THRUSFIELD, M. Veterinary epidemiology. London : Butterworth, 1986. 280p. Cap. 16: Serological Epidemiology: p.175-185.

Van OIRSCHOT, J.T., BRUSCHKE, C.J.M., Van RINJ, P.A. Vaccination of cattle against bovine viral diarrhoea. Vet Microbiol, v.64, p.169-183, 1999.

VOGEL, F.S.F., FLORES, E.F., WEIBLEN, R., et al. Magnitude, duração e especificidade da resposta sorológica em bovinos vacinados contra o vírus da Diarréia Viral Bovina (BVDV). Ciência Rural, v.32, n.1, 2001. (aceito para publicação). 